\title{
Pengaruh Model Pembelajaran CIRC Berbasis Karakter terhadap Kompetensi Pengetahuan IPS
}

\author{
Ni Nyoman Rai Sawitri1*, Ni Wayan Suniasih², I Wayan Sujana3
}

\author{
1 Jurusan PGSD Universitas Pendidikan Ganesha Singaraja, Indonesia \\ 2 Jurusan PGSD Universitas Pendidikan Ganesha Singaraja, Indonesia \\ ${ }_{3}^{3}$ Jurusan PGSD Universitas Pendidikan Ganesha Singaraja, Indonesia
}

\section{Abstrak}

Tujuan penelitian ini adalah untuk mengetahui pengaruh model pembelajaran cooperative integrated reading and composition (CIRC) berbasis karakter terhadap kompetensi pengetahuan IPS siswa kelas IV SDN Gugus Pattimura Denpasar Selatan tahun pelajaran 2017/2018. Jenis penelitian ini adalah eksperimen semu menggunakan rancangan kelompok nonequivalent control group design. Populasi penelitian ini adalah seluruh siswa kelas IV SDN Gugus Pattimura Denpasar Selatan yang berjumlah 301 orang. Sampel ditentukan menggunakan teknik random sampling dengan mengacak kelas. Sampel yang didapatkan disetarakan terlebih dahulu menggunakan teknik matching. Penentuan kelompok eksperimen dan kontrol dilakukan dengan cara mengundi sehingga diperoleh siswa kelas IV SDN 11 Sesetan sebagai kelompok eksperimen dan siswa kelas IV SDN 1 Sesetan dengan jumlah 30 siswa sebagai kelompok kontrol. Data kompetensi pengetahuan IPS dikumpulkan dengan instrumen berupa tes objektif bentuk pilihan ganda biasa yang berjumlah 32 butir tes yang telah divalidasi. Data kompetensi pengetahuan IPS dianalisis dengan menggunakan uji-t. Hasil analisis data diperoleh thitung $=3,52$ sedangkan pada taraf signifikansi $5 \%$ dan $\mathrm{dk}=58$ diperoleh harga ttabel $=2,000$ sehingga thitung $=3,52>$ ttabel $=2,000$. Jadi dapat disimpulkan bahwa terdapat pengaruh model pembelajaran cooperative integrated reading and composition (CIRC) berbasis karakter terhadap kompetensi pengetahuan IPS siswa kelas IV SDN Gugus Pattimura Denpasar Selatan tahun pelajaran 2017/2018.
\end{abstract}

\section{Keywords:}

cooperative integrated reading and composition, karakter, kompetensi pengetahuan IPS

\section{PENDAHULUAN}

Pendidikan merupakan sesuatu yang penting dalam kehidupan. Menurut Sugiartini (2013), "pendidikan dipandang sebagai proses yang sangat bermanfaat di dalam kehidupan yang bukan sematamata hanya sebagai persiapan untuk melanjutkan ke jenjang yang lebih tinggi". Melalui pendidikan dapat meningkatkan kualitas sumber daya manusia, oleh karena itu pendidikan hendaknya dikelola dengan baik agar kualitas dan kuantitasnya juga baik karena pendidikan memegang peranan penting dalam meningkatkan sumber daya yang berkualitas. Dengan adanya pembelajaran menarik yang dirancang oleh guru dan menanamkan nilai-nilai karakter maka dapat merangsang dan membangkitkan semangat siswa dalam belajar.

Kompetensi pengetahuan dapat mengukur sejauh mana siswa menguasai muatan materi yang mereka pelajari, salah satunya adalah muatan materi IPS. Pendidikan IPS di sekolah dasar adalah hal yang penting untuk meningkatkan kepekaan siswa dalam lingkungan sekitarnya. Untuk mencapai tujuan dari pendidikan IPS tersebut maka diperlukan pembelajaran yang menarik bagi siswa, karena dalam muatan materi IPS siswa cenderung bosan dalam belajar, karena banyaknya materi yang harus dipelajari siswa dan materi tersebut bersifat hafalan. Pembelajaran yang dilaksanakan masih berpusat pada guru. Selain itu dalam proses belajar siswa terkadang sulit dalam mengemukakan pendapatnya di depan umum. Jadi dalam hal ini guru mempunyai peranan yang penting dalam mendampingi siswa agar dapat menguasai materi pelajaran dengan cara yang mudah dimengerti, memberikan kesempatan kepada siswa untuk mengemukakan pendapatnya secara merata dan tidak hanya menunjuk orang tertentu saja. 
Menurut Anderson dan Krathwohl (dalam Yusuf, 2015) menyatakan bahwa, "dimensi pengetahuan (knowledge) yang dibedakan atas empat kelompok, yaitu pengetahuan fakta (factual knowledge), pengetahuan konsep (conceptual knowledge), pengetahuan prosedural (procedural knowledge), dan pengetahuan meta-kognitif (meta cognitive knowledge)". Nurgiantoro (2016) menyampaikan pengertian dari keempat dimensi tersebut, yaitu a) pengetahuan fakta merupakan disiplin ilmu dasar yang harus diketahui untuk menjamin kompetensi pengetahuan dan dapat membantu memecahkan masalah, b) pengetahuan konseptual merupakan pengetahuan yang terkait untuk menghubungkan elemen dasar dengan yang lebih besar sehingga mendukung fungsi secara bersamaan, pengetahuan konseptual dibedakan menjadi tiga yaitu pengetahuan klasifikasi, prinsip dan generalisasi, serta teori dan model. c) Pengetahuan prosedural merupakan pengetahuan yang berkaitan dengan proses atau prosedur untuk menghasilkan produk, contohnya cara atau teknik dalam pengembangan wacana. d) Pengetahuan metakognitif merupakan pengetahuan mengenai kesadaran terhadap pengetahuan yang dimiliki, apa yang diketahui dan tidak diketahui. Berdasarkan paparan tersebut dapat disimpulkan bahwa kompetensi pengetahuan IPS merupakan kemampuan siswa dalam memahami materi IPS pada dimensi pengetahuan faktual dan konseptual yang melibatkan kemampuan berfikir pada tingkatan mengingat, memahami, menerapkan, menganalisis.

Slameto (2010) mengemukakan bahwa ada dua faktor yang mempengaruhi hasil belajar, yaitu faktor internal dan faktor eksternal. Faktor internal adalah faktor yang bersumber dari dalam diri siswa sedangkan faktor eskternal adalah faktor yang bersumber dari luar diri siswa. Contoh dari faktor internal adalah kesiapan siswa dan bakat siswa. Sedangkan contoh dari faktor eksternal adalah keluarga, sekolah, dan masyarakat.

Salah satu model pembelajaran yang menyenangkan dan dapat membuat siswa menjadi aktif didalam kelas adalah model pembelajaran Cooperative Integrated Reading and Composition-CIRC (Kooperatif Terpadu Membaca dan Menulis). Menurut Sugiartini (2013), " model pembelajaran cooperative integrated reading and composition (CIRC) dapat pula merangsang dan menggugah potensi siswa secara optimal dalam suasana belajar pada kelompok-kelompok sosial". Sedangkan menurut Abidin (2012: 92), "CIRC pada dasarnya bertujuan untuk menggali kemampuan siswa dalam memahami isi bacaan sekaligus membina kemampuan menulis reproduksi atas bahan bacaan yang dibacanya".

Model pembelajaran CIRC memiliki beberapa kelebihan antara lain kegiatan pembelajaran akan menjadi lebih bermakna karena siswa terlibat langsung untuk mengeluarkan pendapat dan berdiskusi di dalam kelompok, siswa menjadi lebih aktif dan dapat membangkitkan motivasi siswa dalam belajar. Selain beberapa kelebihan yang sudah dijabarkan diatas, model pembelajaran Cooperative Integrated Reading and Composition (CIRC) juga memiliki kekurangan, "dalam model pembelajaran ini hanya dapat dipakai untuk mata pelajaran yang menggunakan bahasa, sehingga model ini tidak dapat dipakai untuk mata pelajaran seperti : matematika dan mata pelajaran lain yang menggunakan prinsip hitung" (Kurniasih \& Sani, 2017: 91). Sugiartini (2013) "Selain itu dengan model Pembelajaran Cooperative Integrated Reading and Composition (CIRC) dapat pula merangsang dan menggugah potensi anak secara optimal dalam suasana belajar pada kelompok-kelompok sosial". Marlitasari (2013) "CIRC akan memberikan pembelajaran yang lebih berarti dan bermakna bagi siswa. Siswa termotivasi untuk belajar, meningkatkan pengalaman dan pengetahuan belajar, serta dapat meningkatkan cara berpikir kritis, kreatif dan menumbuhkan rasa sosial yang tinggi sehingga mampu meningkatkan hasil belajar matematika, khususnya hasil belajar dalam memecahkan soal cerita matematika". "CIRC terdiri dari tiga unsur penting yaitu kegiatan-kegiatan dasar terkait, pengajaran langsung pelajaran memahami bacaan, dan seni berbahasa dan menulis terpadu" (Suantini, 2013). "CIRC adalah salah satu model pengajaran membaca yang muncul dari sebuah penemuan penelitian yang menekankan program pembelajaran kooperatif terpadu antara membaca, menulis dan seni berbahasa" (Widiasih, 2013). Sedangkan Wedayanti (2013) mengatakan bahwa "Model pembelajaran CIRC dikembangkan untuk meningkatkan kesempatan siswa untuk membaca dengan keras dan menerima umpan balik dari kegiatan membaca, dengan membuat para siswa membaca untuk teman satu timnya dan melatih siswa dalam kelompok mengenai saling merespons kegiatan membaca siswa". Sukaryantini (2013) "Pembelajaran kooperatif tipe CIRC dari segi bahasa dapat diartikan sebagai suatu model pembelajaran kooperatif yang mengintegrasikan suatu bacaan secara menyeluruh kemudian mengkomposisikannya menjadi bagianbagian yang penting".

Di dalam CIRC ini, para siswa bekerja dalam kelompok yang heterogen. Pembelajaran dengan model CIRC ini dapat melatih siswa untuk saling bekerja sama didalam kelompok dan untuk saling bertanggung jawab pada kewajiban sendiri. Model pembelajaran CIRC memiliki langkah-langkah dalam pembelajaran diantaranya a) guru menjelaskan tujuan pembelajaran saat itu, kemudian membentuk siswa menjadi beberapa kelompok secara heterogen yang anggotanya terdiri dari 4-6 siswa, b) guru memberikan teks wacana sesuai dengan topik pembelajaran (mengamati), c) siswa bekerja sama dalam 
kelompok untuk menemukan ide pokok dan memberikan tanggapan terhadap teks wacana yang telah dibaca lalu menuliskan pada selembar kertas (menalar \& mengumpulkan informasi), d) perwakilan masing-masing kelompok secara bergiliran membacakan hasil diskusinya di depan kelas (mengkomunikasikan) e) guru memberikan kesempatan kepada siswa untuk bertanya (menanya), f) guru memberikan penguatan, g) guru dan siswa bersama-sama membuat kesimpulan, h) guru menutup pelajaran

Pendidikan karakter di SD sangat penting diterapkan untuk mengembalikan karakter generasi bangsa Indonesia yang sudah mulai luntur. Ini merupakan suatu hal yang sangat penting mengingat bahwa siswa didik adalah generasi penerus bangsa yang akan menentukan nasib bangsa di masa yang akan datang. Lebih baik karakter siswa didik dibentuk sejak sekarang dan diberikan dorongan atau motivasi agar karakter siswa terbentuk dengan baik. Menurut Suyanto (dalam Wibowo, 2012: 33) menyatakan bahwa "karakter adalah cara berfikir dan berprilaku yang menjadi ciri khas tiap individu untuk hidup dan bekerja sama, baik dalam lingkup keluarga, masyarakat, bangsa dan negara". Sedangkan menurut (Yaumi, 2014) bahwa karakter mencakup keinginan seseorang untuk melakukan yang terbaik, kepedulian terhadap kesejahteraan orang lain, dan dapat menyebabkan kemampuan seseorang untuk bekerja sama secara efektif dengan orang lain di dalam situasi tertentu. Jadi dapat disimpulkan bahwa karakter adalah sifat-sifat kejiwaan, akhlak atau budi pekerti yang membedakan seseorang dengan lainnya. Dengan karakter itulah kualitas pribadi seseorang diukur. Menurut Peraturan Presiden Nomor 87 Pasal 3 Tahun 2017, Penguatan Pendidikan Karakter (PPK) dilakssiswaan dengan menerapkan nilai-nilai Pancasila dalam pendidikan karakter terutama meliputi nilai-nilai religius, jujur, toleran, disiplin, bekerja keras, kreatif, mandiri, demokratis, rasa ingin tahu, semangat kebangsaan, cinta tanah air, menghargai prestasi, komunikatif, cinta damai, gemar membaca, peduli lingkungan, peduli sosial, dan bertanggung jawab. Yang sekarang telah diciutkan menjadi 5 karakter untuk menumbuh kembangkan moral dan etika bangsa. Kelima karakter tersebut adalah (a) religius, dimana sikap dan prilaku yang patuh dalam melakssiswaan ajaran agama yang dianutnya, toleran terhadap pelaksanaan ibadah, serta hidup rukun dengan pemeluk agama lain, (b) nasionalis, dimana seseorang mempunyai jiwa semangat kebangsaan, cara berfikir dan bersikap yang menunjukkan kesetiaan terhadap bangsa, (c) integritas, dimana sikap seseorang yang dapat menghargai perbedaan agama, suku, dan tindakan orang lain yang berbeda dengan dirinya, (d) mandiri, merupakan sikap dan prilaku yang tidak mudah tergantung pada orang lain dalam menyelesaikan tugas-tugas, (e) gotong royong.

Berdasarkan uraian tersebut dapat disimpulkan model pembelajaran Cooperative Integrated Reading and Composition (CIRC) berbasis karakter merupakan model pembelajaran dengan cara siswa belajar secara berkelompok dimana setiap siswa mendapatkan kesempatan untuk mengemukakan ide-ide untuk memahami suatu tugas yang telah diberikan. Model pembelajaran ini bertujuan untuk meningkatan keinginan siswa untuk membaca dan menuliskan hasil diskusinya pada selembar kertas dimana dalam proses pembelajarannya menanamkan nilai-nilai karakter.

\section{METODE PENELITIAN}

Penelitian dilaksanakan di kelas IV SDN Gugus Pattimura Denpasar Selatan Kecamatan Denpasar Selatan. Jenis penelitian yang dilakukan ini adalah eksperimen. Desain penelitian eksperimen ini adalah quasi eksperimen design. Dalam penelitian ini rancangan penelitian yang digunakan adalah Nonequivalent Control Group Design. Dalam sebuah penelitian, pemilihan polulasi merupakan hal yang sangat perlu dilakukan. "Populasi adalah wilayah generalisasi yang terdiri atas: obyek/subyek yang mempunyai kualitas dan karakteristik tertentu yang ditetapkan oleh penelitian untuk dipelajari dan kemudia ditarik kesimpulannya" (Sugiyono, 2009: 117). Populasi dalam penelitian ini adalah seluruh siswa kelas IV SD Sesetan Gugus Pattimura tahun pelajaran 2017/2018. Jumlah populasi dari penelitian ini adalah 301 orang.

Setelah menentukan populasi yang akan digunakan, selanjutnya adalah menentukan sampel penelitian. "Sampel adalah bagian dari jumlah dan karakteristik yang dimiliki oleh populasi tersebut (Sugiyono, 2009: 118). Dengan teknik random diperoleh dua kelompok siswa yang dijadikan sampel penelitian yang selanjutnya diundi untuk menentukan kelompok eksperimen dan kelompok kontrol. Sebelum diberikan perlakuan kedua kelompok tersebut disetarakan dengan teknik matching dan mendapatkan hasil 30 siswa yang memiliki kemampuan yang setara secara akademik. Setelah diketahui kedua kelompok setara, maka dilakukan pengundian lagi dari 2 kelompok yang setara untuk memilih nama sekolah yang digunakan sebagai kelompok eksperimen dan kelompok kontrol. Berdasarkan hasil undian, diperoleh kelas IV SD Negeri 11 Sesetan sebagai kelompok eksperimen dan kelas IV SD Negeri 1 Sesetan sebagai kelas kontrol. 
Dalam penelitian ini data yang dikumpulkan adalah data kompetensi pengetahuan IPS siswa kelas IV. Untuk mengumpulkan data. Digunakan metode tes objektif pilihan ganda biasa. Untuk mengetahui layak atau tidaknya instrument yang digunakan terlebih dahulu divalidasi yang meliputi uji validitas, uji daya beda, uji tingkat kesukaran, uji reliabilitas. Berdasarkan hasil analisis diperoleh hasil 32 butir tes yang valid. Selanjutnya dilakukan uji daya beda untuk mengetahui kemampuan butir tes tersebut membedakan antara tes kelompok atas (pintar) dan tes kelompok bawah (lemah). Untuk menentukan kelompok atas dan kelompok bawah dari testi yang sudah digunakan adalah dengan cara mengurutkan skor setiap testi dari skor yang tertinggi sampai dengan skor yang terendah . Kemudian diambil $50 \%$ kelompok atas dan 50\% kelompok bawah. Berdasarkan analisis daya beda tes menggunakan Microsoft office excel 2007 diperoleh 3 butir tes dengan kriteria baik sekali, 10 butir tes dengan kriteria baik, dan 19 butir soal dengan kriteria cukup. Tingkat kesukaran dapat dipandang sebagai kesanggupan atau kemampuan siswa menjawab tes yang diberikan. Dalam penlitian ini, analisis tingkat kesukaran butir tes menggunakan Microsoft office excel 2007 diperoleh hasil 24 butir tes dengan kriteria sedang, diperoleh 3 butir tes dengan kriteria mudah, ) dan 5 butir tes dengan kriteria sukar. Selanjutnya adalah uji reliabilitas. Uji reliabilitas dilakukan terhadap butir tes yang valid saja. Jadi uji reliabilitas ini dapat dilakukan setelah melakukan uji validitas. Dalam penelitian ini, analisis reliabilitas soal posttest menggunakan Microsoft office excel 2007. Berdasarkan analisis diperoleh hasil r11 0, 925. Hal ini berarti tes yang diujikan tergolong reliabel.

Data dianalisis dengan menggunakan uji-t. Sebelum dilakukan uji-t maka dilakukan uji prasyarat analisis yaitu uji normalitas dan uji homogenitas. "Penggunaan statistik parametris mensyaratkan bahwa data setiap variabel yang akan dianalisis harus berdistribusi normal. Oleh karena itu sebelum menguji hipotesis dilakukan, maka akan terlebih dahulu akan dilakukan pengujian normalitas data" (Sugiyono, 2009: 241). Pengujian normalitas data dilakukan dengan menggunakan rumus chi-square. Kriteria pengujian yaitu jika $\mathrm{X}^{2}$ hitung $\leq \mathrm{X}^{2}$ tabel, maka $\mathrm{H}_{\mathrm{o}}$ diterima (gagal ditolak) dan $\mathrm{H}_{\mathrm{a}}$ ditolak yang berarti sebaran data berdistribusi normal pada taraf signifikansi 5\% dan dk (k-1). Untuk menguji homogenitas varians suatu data dilakukan dengan menggunakan uji F dari Havley yaitu varians terbesar dibagi varians terkecil. Kriteria dalam pengujian ini adalah : jika $\mathrm{F}$ hitung $\leq \mathrm{F}$ tabel, maka kedua kelompok data homogen. Sebaliknya jika $\mathrm{F}$ hitung > Ftabel, maka kedua kelompok data tidak homogen. Harga $\mathrm{F}$ hitung dibandingkan dengan $\mathrm{F}$ tabel pada taraf signifikansi 5\% dengan $\mathrm{df}=\mathrm{k}-1$.

Setelah melakukan uji prasyarat analisis, kemudian dilakukan uji hipotesis yang telah dirumuskan, maka digunakan analisis statistic uji-t.

\section{ANALISIS DAN PEMBAHASAN}

Berdasarkan hasil perhitungan untuk uji prasyarat analisis data kompetensi pengetahuan IPS diperoleh nilai rata-rata kompetensi pengetahuan IPS kelompok eksperimen $\mathrm{X}=82,10$, dengan varians adalah $S^{2}=138,78$, nilai minimum adalah 56 dan nilai maksimum adalah 97. Sedangkan nilai rata-rata kompetensi pengetahuan IPS kelompok kontrol $X=72,13$, dengan varians adalah $\mathrm{S}^{2}=103,84$.

Uji normalitas menggunakan rumus Chi Square pada kelompok eksperimen diperoleh $\mathrm{X}^{2}{ }_{\text {hitung }}=3,89$ dan dengan taraf siginifikansi $5 \%$ dan dk (k-1) diperoleh $\mathrm{X}^{2}$ tabel $=11,07$. Karena $\mathrm{X}^{2}{ }_{\text {hitung }}=3,89<\mathrm{X}^{2}$ tabel $=$ 11,07 , sehingga $H_{0}$ diterima yang berarti data kompetensi pengetahuan IPS kelompok eksperimen berdistribusi normal. Sedangkan pada kelompok kontrol diperoleh $\mathrm{X}^{2}$ hitung $=2,86$ dan dengan taraf siginifikansi 5\% dan dk (k-1) diperoleh $\mathrm{X}^{2}$ tabel $=11,07$. Karena $\mathrm{X}^{2}{ }_{\text {hitung }}=2,86<\mathrm{X}^{2}$ tabel $=11,07$, sehingga $\mathrm{H}_{0}$ diterima yang berarti data kompetensi pengetahuan IPS kelompok kontrol berdistribusi normal. Sehingga dapat dikatakan kompetensi pengetahuan IPS setelah dianalisis menggunakan Chi Square baik kelompok eksperimen maupun kelompok kontrol berdistribusi normal.

Uji homogenitas varian ini dilakukan berdasarkan data kompetensi pengetahuan IPS kelompok esperimen dan kelompok kontrol . Uji homogenitas varian menggunakan uji F. Pada taraf signifikansi 5\% dengan derajat kebebasan $(\mathrm{dk})$ untuk pembilang $\mathrm{n}_{1}-1(30-1=29)$ dan derajat kebebasan (dk) untuk penyebut $\mathrm{n}_{2}-1(30-1=29)$ diperoleh $\mathrm{F}_{\text {tabel }}=1$,85. Dari hasil analisis, diperoleh $\mathrm{F}_{\text {hitung }}=1,34$. Hal ini berarti $F_{\text {hitung }}=1,34<F_{\text {tabel }}=1,85$ sehingga data kedua kelompok memiliki varians yang homogen. Berdasarkan hasil uji prasyarat yang terdiri dari uji normalitas dan uji homogenitas varians dapat disimpulkan bahwa data kedua kelompok sampel berdistribusi normal dan memiliki varians yang homogen. Dengan demikian, uji hipotesis menggunakan uji-t dapat dilakukan.

Hipotesis dalam penelitian ini yaitu tidak terdapat pengaruh model pembelajaran cooperative integrated reading and composition (CIRC) berbasis karakter terhadap kompetensi pengetahuan IPS siswa kelas IV SDN Gugus Pattimura Denpasar Selatan Tahun Pelajaran 2017/2018. Berdasarkan kriteria pengujian uji-t diperoleh $t_{\text {hitung }}=3,52$. Pada taraf signifikansi $5 \%$ dan $\mathrm{dk}=30+30-2=58$ maka diperoleh harga $t_{\text {tabel }}=2,000$. Dengan demikian diperoleh $t_{\text {hitung }}=3,52>t_{\text {tabel }}=2,000$. 
Maka $\mathrm{H}_{0}$ yang menyatakan tidak terdapat pengaruh model pembelajaran cooperative integrated reading and composition (CIRC) berbasis karakter terhadap kompetensi pengetahuan IPS siswa kelas IV SDN Gugus Pattimura Denpasar Selatan Tahun Pelajaran 2017/2018 ditolak dengan X = 82,10 $>$ X = 72,13 memiliki perbedaan sebesar 9,97. Hal tersebut berarti terdapat pengaruh model pembelajaran cooperative integrated reading and composition (CIRC) berbasis karakter terhadap kompetensi pengetahuan IPS siswa kelas IV SDN Gugus Pattimura Denpasar Selatan Tahun Pelajaran 2017/2018.

Pada umumnya pembelajaran IPS di kelas eksperimen yang dibelajarkan melalui model pembelajaran cooperative integrated reading and composition (CIRC) berbasis karakter sudah berjalan dengan baik dan kondusif. Hal ini disebabkan oleh adanya perbedaan perlakuan yang diberikan pada kelompok eksperimen maupun kelompok kontrol. Model pembelajaran CIRC berbasis karakter ini merupakan suatu model pembelajaran yang mendorong siswa untuk aktif di dalam kelompok untuk mengemukakan pendapat yang mereka miliki dalam menanggapi suatu permasalahan atau materi yang diberikan dengan menanamkan nilai-nilai karakter. Pada saat siswa belajar dalam kelompok akan berkembang pola belajar secara tutor sebaya dan interaksi yang terjadi di dalam kelompok dapat melatih siswa untuk berani berpendapat, menerima dan menghargai pendapat dari teman. Dengan demikian siswa memiliki bekal bekeranian berpendapat dalam suatu interaksi dalam kehidupannya di masyarakat yang sesuai dengan tujuan pembelajaran Ilmu Pengetahuan Sosial. Adapun karakter yang dikembangkan yaitu religigus, nasionalis, integritas, mandiri dan gotong royong.

Penelitian yang dilakukan oleh Suarjana (2014) menyatakan bahwa terdapat perbedaan yang signifikan hasil belajar Matematika antara siswa yang mengikuti pembelajaran Cooperative Integrated Reading and Composition berbasis soal cerita dengan siswa yang mengikuti pembelajaran konvensional. Hal tersebut dapat dibuktikan melalui analisis statistik yang digunakan untuk menguji hipotesis yaitu uji beda mean (uji-t) diperoleh thitung $=4,20>$ ttabel $=2,000$. Kajian penelitian tersebut adalah sama-sama meneliti tentang pengaruh model pembelajaran Cooperative Integrated Reading and Composition. Sedangkan perbedaannya adalah dalam penelitian Suarjana menggunakan model pembelajaran CIRC berbasis soal cerita, penelitian ini menggunakan model pembelajaran CIRC berbasis karakter. Penelitian Suarjana memfokuskan penelitian terhadap hasil belajar Matematika, sedangkan penelitian ini meneliti kompetensi pengetahuan IPS.

Penelitian yang dilakukan oleh Yudasmini (2015) menyatakan (1) terdapat perbedaan minat baca siswa yang mengikuti model pembelajaran CIRC dengan siswa yang mengikuti pembelajaran konvensional paa siswa kelas VI di Sekolah Dasar Gugus Buruan, (2) terdapat perbedaan kemampuan memahami bacaan siswa yang mengikuti model pembelajaran CIRC dengan siswa yang mengikuti pembelajaran konvensional pada siswa kelas VI di Sekolah Daar Gugus Buruan, dan (3) terdapat perbedaan secara bersama-sama minat baca dan kemampuan memahami bacaan siswa yang mengikuti model pembelajaran CIRC dengan siswa yang mengikuti pembelajaran konvensional pada siswa kelas VI di Sekolah Dasar Gugus Buruan. Hal tersebut dapat dibuktikan melalui metode analisis data yang digunakan yaitu Manova satu jalan.

Kajian penelitian tersebut adalah sama-sama meneliti tentang model pembelajaran Cooperative Integrated Reading and Composition. Sedangkan perbedaannya adalah penelitian Yudasmini memfokuskan penelitian terhadap minat baca dan kemampuan memahami bacaan, sedangkan penelitian ini meneliti kompetensi pengetahuan IPS.

Dengan demikian, pembelajaran menggunakan model pembelajaran Cooperative Integrated Reading and Composition (CIRC) berbasis karakter pada penelitian ini memiliki keunggulan yaitu dapat membangkitkan semangat siswa dalam belajar pada muatan materi IPS, membangkitkan kemampuan berfikir siswa karena siswa diberikan kesempatan untuk mengemukakan pendapatnya di dalam kelompok dan saling bertukar fikiran dengan teman dalam suatu kelompok yang didukung oleh peranan guru dalam menerapkan suatu pembelajaran dengan menanamkan nilai-nilai karakter.

\section{KESIMPULAN}

Berdasarkan uji hipotesis $t_{\text {hitung }}=3,52$ sedangkan pada taraf signifikasi $5 \%$ dan dk $=58$ diperoleh nilai $t_{\text {tabel }}=2,000$ sehingga $t_{\text {hitung }}=3,52>t_{\text {tabel }}=2,000$ ini berarti terdapat pengaruh model pembelajaran cooperative integrated reading and composition (CIRC) berbasis karakter terhadap kompetensi pengetahuan IPS siswa kelas IV SDN Gugus Pattimura Denpasar Selatan Tahun Pelajaran 2017/2018). Perolehan hasil perhitungan analisis data yang dilakukan menunjukkan bahwa nilai rerata siswa di kelompok eksperimen (CIRC) berbasis karakter $(=82,10)$ dan siswa yang mengikuti pembelajaran dikelompok kontrol $(=72,13)$ memiliki perbedaan sebesar 9,97. Dengan demikian, terdapat pengaruh model pembelajaran cooperative integrated reading and composition (CIRC) berbasis karakter terhadap 
kompetensi pengetahuan IPS siswa kelas IV SDN Gugus Pattimura Denpasar Selatan Tahun Pelajaran $2017 / 2018$.

Berdasarkan hasil penelitian ini, maka dapat diajukan beberapa saran sebagai tindak lanjut dari penelitian ini. Saran diajukan kepada guru mencoba untuk menerapkan model pembelajaran cooperative integrated reading and composition (CIRC) berbasis karakter secara lebih lanjut untuk lebih meningkatkan kerjasama antara siswa dengan guru, siswa dengan siswa sehingga dapat meningkatkan kualitas pembelajaran sesuai dengan harapan

\section{DAFTAR PUSTAKA}

Abidin, Yunus. 2012. Pembelajaran Membaca Berbasis Pendidikan Karakte. Bandung: Refika Aditma.

Kartika, Cokorda Istri \& Tjok Rai Partadjaya, I W. Widiana. "Pengaruh Model Pembelajaran Circ Berbasis Jolly Phonics Terhadap Kemampuan Membaca Dan Menulis Siswa Kelas Ii Sd Gugus Ii Kecamatan Sukawati". Jurnal Mimbar PGSD Vol 1 No 12013 (186).

Kurniasih, Imas dan Berlin. Sani. 2016. Ragam Pengembangan Model Pembelajaran. Kata Pena.

Marlitasari, Ni Pt. Rima \& A. A. Gede Agung, Ign. I Wyn. Suwatra. 2013. "Pengaruh Model Pembelajaran Kooperatif Tipe Circ Terhadap Hasil Belajar Matematika Pada Siswa Kelas V Di Sd Gugus Viii Kecamatan Mengwi”. Jurnal Mimbar PGSD Vol 1 No 12013 (84).

Nurgiantoro. 2016. Penilaian Pembelajaran Bahasa Berbasis Kompetensi. Yogyakarta. BPFE-Yogyakarta

Prabawati, I Gst. Ayu Dewi Chandra \& Ni Nym. Garminah, I Wyn. Widiana. 2013 "Pengaruh Model Circ Berbantuan Media Gambar Berseri Terhadap Kemampuan Membaca Pemahaman Pada Siswa Kelas V Sd Gugus Iv Kecamatan Rendang. Jurnal Mimbar PGSD Vol 1 No 12013 (26).

Slameto. 2010. Belajar dan Faktor-faktor yang Mempengaruhi. Jakarta: Rineka Cipta.

Suantini,Ni L.P.Yuni \& I Nym. Jampel, I Wyn. Widiana. 2013. "Pengaruh Model Pembelajaran Kooperatif Tipe Circ Terhadap Pemahaman Konsep Ipa Siswa Kelas Iv Di Gugus Ii Kecamatan Gerokgak”. Jurnal Mimbar PGSD Vol 1 No 12013 (64).

Suarjana. 2014. "Pengaruh Model CIRC Berbasis Soal Cerita Terhadap Hasil Belajar Matematika Siswa Kelas V SD Gugus 1 Kecamatan Gianyar" Universitas Pendidikan Ganesha. Vol: 2 No 12014 hal 86

Sugiyono, 2009. Metode Penelitian Pendidikan Penekatan Kuantitatif, Kualitatif, dan R\&D. Bandung: Alfabeta.

Sugiartini, Ni Kt Ratna \& Ni Ngh Madri Antari2, I Kd Suartama.2013. "Pengaruh Model Pembelajaran Cooperative Integrated Reading And Composition (Circ) Terhadap Hasil Belajar Ips Kelas Iv Gugus I Kecamatan Manggis". Jurnal Mimbar PGSD Vol 1 No 12013 (124).

Sukaryantini , Ni Made Mas. 2013. “Upaya Meningkatkan Kemampuan Memahami Nilai-Nilai Edukatif Dalam Cerpen Melalui Model Circ (Cooperative Integrated Reading And Composition) Siswa Kelas Xi Ips1 Di Sma Saraswati Seririt”. Jurnal Pendidikan Bahasa dan Sastra Indonesia Undiksha Vol 1 No 6 2013 (126).

Tristiantari, Ni Ketut Desia dan I Made Sumantri. 2016. "Model Pembelajaran Cooperatif Integrated Reading Composition Berpola Lesson Study Meningkatkan Keterampilan Membaca Dan Menulis". Jurnal Pendidikan Indonesia Vol. 5, No. 2, Oktober 2016 | 203.

Wedayanti, Ni Wyn. \& Anggun I Kt. Adnyana Putra, I Gd. Meter. 2013. "Pengaruh Model Pembelajaran Circ Berbantuan Gambar Berseri Terhadap Keterampilan Membaca Dan Menulis Siswa Kelas Iv Sdn 18 Pemecutan". Jurnal Mimbar PGSD Vol 1 No 12013 (162). 
Widiasih, Ni Pt. Hadomi \& I Nym. Wirya, Kd. Suranata. 2013. "Pengaruh Model Pembelajaran Circ Berbantuan Media Scrabble Terhadap Hasil Belajar Bahasa Bali Siswa Kelas Iv Sd Gugus Ii Kecamatan Buleleng". Jurnal Mimbar PGSD Vol 1 No 12013 (85).

Yudasmini, M. 2015. "Pengaruh Model Pembelajaran CIRC (Cooperative Integrated Reading and Composition) Terhadap Minat Baca dan Kemampuan Memahami Bacaan Pada Siswa Kelas VI di Sekolah Dasar Gugus Buruan" Vol.5

Yusuf, Muri. 2015. Asesmen dan Evaluasi Pendidikan. Jakarta: Prenadamedia Groups 